\title{
INVESTIGATIONS FOR STATISTICALLY CONTROLLED RESISTANCE SPOT WELDING SOLUTION OF STAINLESS STEEL
}

\author{
Rupinder Singh $^{1^{*}}$ and Sunpreet Singh ${ }^{2}$ \\ ${ }^{1}$ Production Engineering Department, GNDEC, Ludhiana, India 141006 \\ ${ }^{2}$ Production Engineering Department, GNDEC, Ludhiana, India 141006 \\ *Corresponding e-mail: rupindersingh78@yahoo.com
}

\begin{abstract}
The purpose of the present investigations is to study statistically controlled solution (from sensitization point of view) for 304 stainless steel (SS) joints using resistance spot welding process (RSWP). Starting from the parametric optimization of RSWP parameters (based upon Taguchi design), welded joints were prepared for functional checking. The output parameters selected for controlling the sensitization were hardness and tensile strength of welded joints. The results are supported by SEM analysis. Further the study suggests that the RSWP was found to be under statistical control (at optimized settings suggested by Taguchi design) as regard to sensitization of welded joint is concerned.
\end{abstract}

Keywords: Resistance spot welding, Statistically controlled, Sensitization, Hardness, Tensile strength.

\section{INTRODUCTION}

Sensitization is a major problem in welding of SS that affects the alloys durability ${ }^{1}$. SS is commonly welded by resistance spot welding process ${ }^{2,3}$. This process requires the application of both heat and pressure to achieve a sound joint. The heat generated depends upon the current/ voltage, the time for which current is passed and the resistance at the interface $e^{4-6}$. The resistance is a function of the resistivity and surface condition of the parent material, the size, shape and material of the electrodes and the pressure applied by the electrodes ${ }^{4}$. The literature review reveals that lot of work has been reported on the optimization of physical/mechanical properties of welded joints and reduction of sensitization during welding of 304 SS by different techniques ${ }^{6-9}$. But hitherto no work has been reported on statistically controlled RSWP based solution of 304SS from sensitization point of view. So, in the present work effort has been made to investigate statistically controlled RSWP solution of 304 SS (based upon Taguchi model) with focus on sensitization. Table 1 and 2 respectively shows chemical composition of workpiece material and input parameters (namely: welding time, voltage and coolant flow rate (CFR) and their levels based upon Taguchi L9 (OA) for investigation of sensitization phenomenon in 304 SS. The output parameter set for study are hardness and tensile strength.

\section{EXPERIMENTATION}

Based upon Table 2 and Table 3 shows observations (with three repitations) for hardness (H1, $\mathrm{H} 2$ and $\mathrm{H} 3$ ) and tensile strength (T1, T2 and $\mathrm{T} 3$ ) of welded joints with RSWP.

Further based upon Table 2 and 3, signal to noise $(\mathrm{S} / \mathrm{N})$ ratios for hardness and tensile strength were obtained from raw data [10]. Table 4 showns the $\mathrm{S} / \mathrm{N}$ ratios for output parameters. The analysis has been made on the basis of maximum the better type case. Now based upon Table 4, Figure-1 shows percentage contribution of input parameters for outputs.

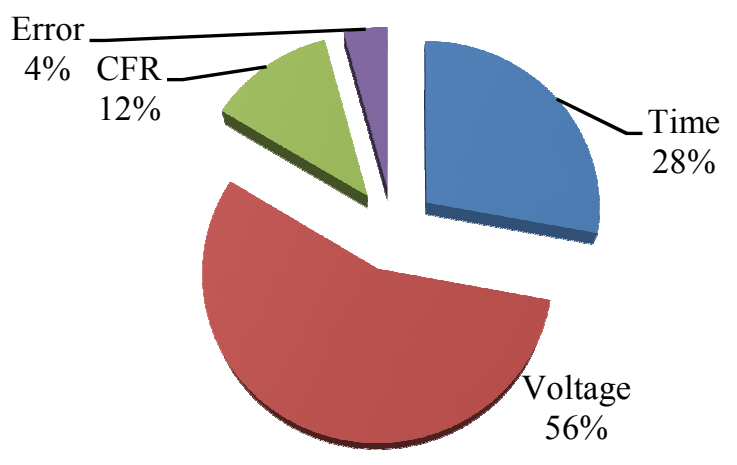

(a)

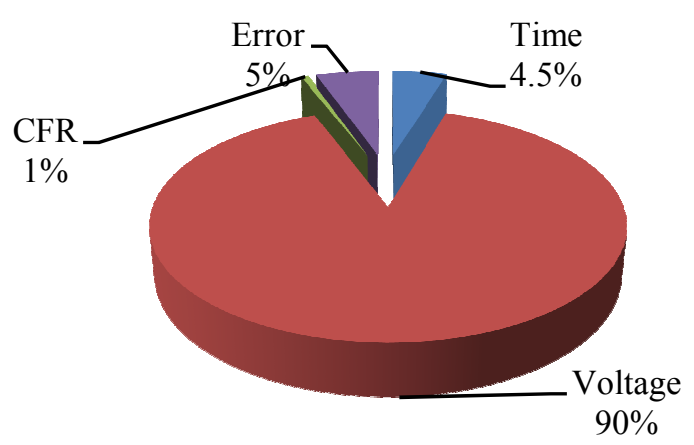

(b)

Figure 1. Percentage contribution of input parameters for (a) hardness and (b)tensile stength. 
Table 1. Chemical composition of 304 SS (\%wt).

\begin{tabular}{ccccccc}
\hline Element & $\mathrm{C}$ & $\mathrm{M}$ & $\mathrm{S}$ & $\mathrm{C}$ & $\mathrm{N}$ & $\mathrm{M}$ \\
\%wt. & 0.035 & 1.08 & 0.388 & 18.47 & 9 & 0.561 \\
\hline
\end{tabular}

Table 2. Input parameter and their levels.

\begin{tabular}{cccc}
\hline S.No. & Time $(\mathrm{sec})$ & Voltage $(\mathrm{V})$ & CFR $\left(\mathrm{m}^{3} / \mathrm{sec}\right)$ \\
\hline 1 & 1 & 2 & 0.0277 \\
2 & 1 & 2.5 & 0.0297 \\
3 & 1 & 3 & 0.0317 \\
4 & 1.5 & 2 & 0.0297 \\
5 & 1.5 & 2.5 & 0.0317 \\
6 & 1.5 & 3 & 0.0277 \\
7 & 2 & 2 & 0.0317 \\
8 & 2 & 2.5 & 0.0277 \\
9 & 2 & 3 & 0.0297 \\
\hline
\end{tabular}

Table 3. Observations for hardness and tensile strength of welded joints.

\begin{tabular}{cccccc}
\hline \multicolumn{3}{c}{$\begin{array}{c}\text { Hardness } \\
\text { (HRC) }\end{array}$} & \multicolumn{3}{c}{$\begin{array}{c}\text { Tensile strength } \\
\text { (kgf) }\end{array}$} \\
\hline H1 & H2 & H3 & T1 & T2 & T3 \\
66 & 63 & 64 & 600 & 580 & 610 \\
69 & 72 & 70 & 760 & 720 & 750 \\
71 & 73 & 72 & 920 & 930 & 890 \\
73 & 72 & 69 & 620 & 650 & 690 \\
74 & 71 & 69 & 830 & 840 & 870 \\
75 & 72 & 73 & 930 & 910 & 900 \\
67 & 71 & 69 & 580 & 620 & 600 \\
73 & 74 & 71 & 960 & 900 & 930 \\
78 & 76 & 75 & 970 & 950 & 940 \\
\hline
\end{tabular}

Table 4. S/N ratios for output parameters.

\begin{tabular}{cc}
\hline S/N for Hardness & S/N for Tensile strength \\
\hline 36.16387 & 55.50888 \\
36.93916 & 57.41675 \\
37.14497 & 59.20801 \\
37.05833 & 56.2778 \\
37.05513 & 58.54907 \\
37.30229 & 59.21017 \\
36.76968 & 55.55337 \\
37.22283 & 59.36061 \\
37.65083 & 59.58268 \\
\hline
\end{tabular}

As observed from Fig. 1 contribution of input parameters for hardness and tensile strength of welded joints is : Voltage ( $56 \%$ and $90 \%)$, CFR $(12 \%$ and $1 \%)$ and Time (28\% and $4.5 \%)$ respectively.

The optimized settings of input parameters for welded joints are as follows:

- For maximum hardness: CFR $0.0297 \mathrm{~m}^{3} / \mathrm{s}$, voltage $3 \mathrm{~V}$ and time $2 \mathrm{sec}$.

- For maximum tensile strength: CFR $0.0277 \mathrm{~m}^{3} / \mathrm{s}$, voltage $3 \mathrm{~V}$ and time $2 \mathrm{sec}$.
The confirmatory experiments (performed at optimized settings as suggested by Taguchi DOE technique) resulted into 81.12HRC-hardness and 999.1kgf-tensile strength. The percentage improvement in hardness and tensile strength of the welding joint was calculated using 78HRC-hardness and 970kgf tensile strength (maximum of Table 3 ) as initial values and 81.12HRC-hardness and 999.1 kgftensile strength as final values (obtained in confirmatory experiment). It has been found that hardness and tensile strength of the welded joint has been improved by $4 \%$ and $3 \%$ respectively. Figure 2 shows SEM images of welded joints at optimized settings. As observed from Figure 2 no sensitization has occurred over the surface on welded joints. The same has been verified by improved hardness and tensile strength.

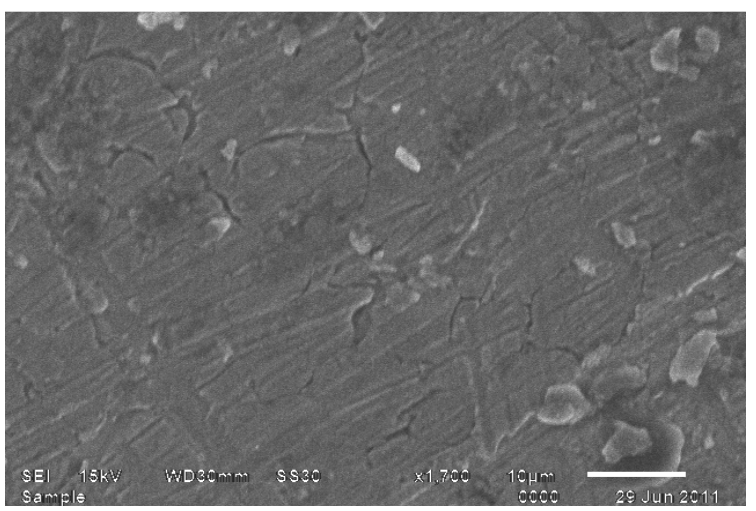

SEM of work piece joint obtained at optimized settings for hardness (81.12HRC)

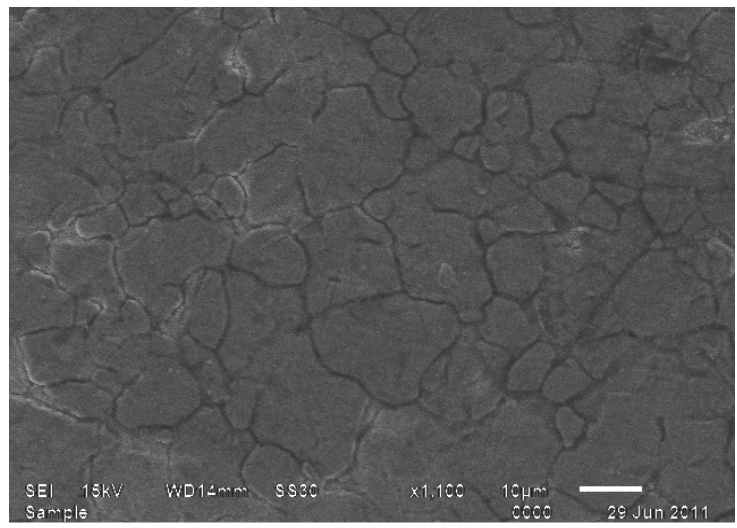

SEM of work piece joint obtained at optimized settings for tensile strength $(999.1 \mathrm{kgf})$

Figure 2. SEM images of welded joints at optimized settings.

\section{ANALYSIS AND DISCUSSION}

Further based upon optimized settings suggested by Taguchi design, to understand whether the process is statistically controlled $(06+06=12)$ welded joint samples were prepared for maximum hardness (with input parameter setting as CFR $0.0297 \mathrm{~m}^{3} / \mathrm{s}$, voltage $3 \mathrm{~V}$ and time $2 \mathrm{sec}$ ) and for maximum tensile strength 
at CFR $0.0277 \mathrm{~m}^{3} / \mathrm{s}$, voltage $3 \mathrm{~V}$ and time $2 \mathrm{sec}$. On measurement of hardness and tensile strength observations are shown in Table 5 and 6 respectively. Based upon Table 5 and 6, Figure-3 and Figure-4 shows run-chart of the observed values of hardness and tensile strength.

Now if the mean and standard of population that is having normal distribution is $\mu$ and $\sigma$ respectively then for variable data $\mathrm{X}$ the standard normal deviate $\mathrm{Z}$ is defined as Eq.1:

$$
Z=\frac{(\mathrm{Xi}-\mu)}{\sigma}
$$

where $X_{i}$ is the variable data obtained, $\mu$ is the mean of data and $\sigma$ is the standard deviation ${ }^{11-13}$.

Table 5. Observed value of hardness (HRC) at optimized settings.

\begin{tabular}{ccccc}
\hline S.N. & Observation & Mean & $\begin{array}{c}\text { Above or } \\
\text { Below } \\
\text { Mean }\end{array}$ & $\begin{array}{c}\text { Up or } \\
\text { Down }\end{array}$ \\
\hline 1 & 78.69 & 78.803 & $\mathrm{~B}$ & \\
2 & 78.75 & 78.803 & $\mathrm{~B}$ & $\mathrm{U}$ \\
3 & 78.79 & 78.803 & $\mathrm{~B}$ & $\mathrm{U}$ \\
4 & 78.86 & 78.803 & $\mathrm{~A}$ & $\mathrm{U}$ \\
5 & 78.84 & 78.803 & $\mathrm{~A}$ & $\mathrm{D}$ \\
6 & 78.89 & 78.803 & $\mathrm{~A}$ & $\mathrm{U}$ \\
Mean & 78.803 & & $\mathrm{E}_{\mathrm{AB}=1}$ & $\mathrm{E}_{\mathrm{UD}=2}$ \\
\hline
\end{tabular}

Table 6. Observed value of tensile strength $(\mathrm{N})$ at optimized settings.

\begin{tabular}{ccccc}
\hline S.N. & Observation & Mean & $\begin{array}{c}\text { Above or } \\
\text { Below } \\
\text { Mean }\end{array}$ & $\begin{array}{c}\text { Up or } \\
\text { Down }\end{array}$ \\
\hline 1 & 9613.80 & 9719.91 & $\mathrm{~B}$ & \\
2 & 9603.99 & 9719.91 & $\mathrm{~B}$ & $\mathrm{D}$ \\
3 & 9682.47 & 9719.91 & $\mathrm{~B}$ & $\mathrm{U}$ \\
4 & 9751.14 & 9719.91 & $\mathrm{~A}$ & $\mathrm{U}$ \\
5 & 9839.43 & 9719.91 & $\mathrm{~A}$ & $\mathrm{U}$ \\
6 & 9828.63 & 9719.91 & $\mathrm{~A}$ & $\mathrm{D}$ \\
Mean & 9719.91 & \multicolumn{5}{c}{$\mathrm{E}_{\mathrm{AB}=1}$} & $\mathrm{E}_{\mathrm{UD}=2}$ \\
\hline Note: A is above the mean, $B$ is below the mean, $U$ is $U p$ \\
from previous reading and D is Down from previous \\
reading.
\end{tabular}

Calculation for $\mathrm{Z}$ (standard normal deviate) above and below has been calculated as Eqn.2:

$$
\mathrm{E}(\text { run })_{\mathrm{AB}}=\left(\frac{\mathrm{N}}{2}+1\right)
$$

Where $\mathrm{N}$ is the number of observations and $\mathrm{E}$ (run) AB $_{\mathrm{B}}$ is the expected number of run above and below.

$$
\begin{aligned}
& \mathrm{E}(\operatorname{run})_{\mathrm{AB}}=\left(\frac{6}{2}+1\right)=4 \\
& \text { And } \sigma_{\mathrm{AB}}=\sqrt{ }\left(N-\frac{1}{4}\right)
\end{aligned}
$$

Where $\sigma_{\mathrm{AB}}$ is the standard deviation of above and below:

$$
\begin{gathered}
\sigma_{\mathrm{AB}}=\sqrt{ }\left(6-\frac{1}{4}\right)=1.118 \\
\text { and } \mathrm{Z}_{\mathrm{AB}}=\left\{\mathrm{RUN}_{\mathrm{AB}}-\mathrm{E}(\text { run })_{\mathrm{AB}}\right\} / \sigma_{\mathrm{AB}}
\end{gathered}
$$

Where $\mathrm{RUN}_{\mathrm{AB}}$ is the actual number of run obtained above and below:

$$
\mathrm{Z}_{\mathrm{AB}}=\frac{(1-4)}{1.118}=-2.6834
$$

$\mathrm{P}_{\mathrm{AB}}=\operatorname{NORMSDIST}(\mathrm{Z})$ when the value of $\mathrm{Z}$ is negative (using microsoft excel software) $\mathrm{P}=0.003645$.

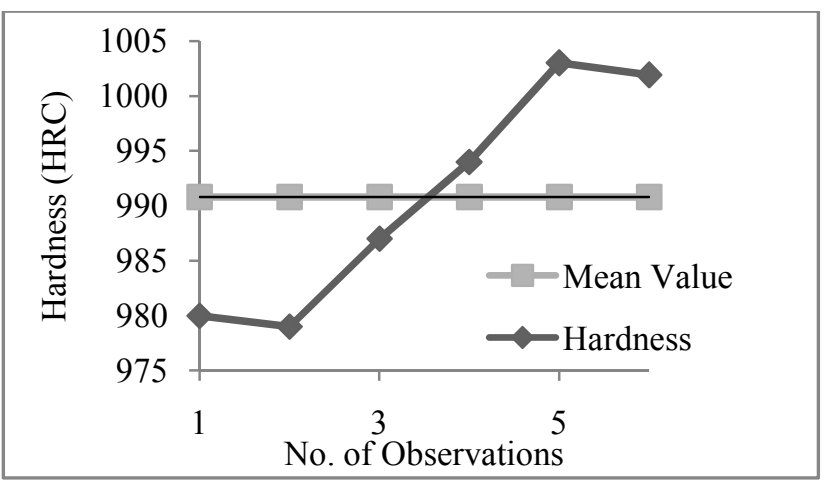

Figure 3. Run-chart of the observed values of hardness.

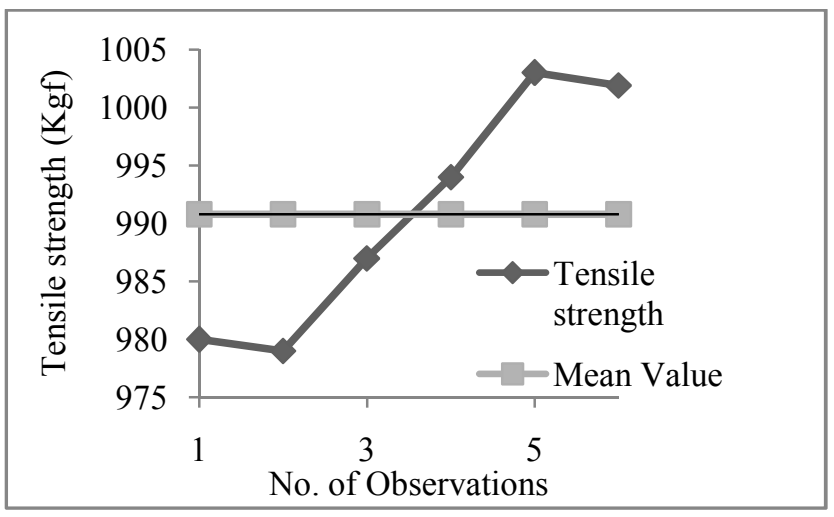

Figure 4. Run-chart of the observed values of tensile strength.

Further for up and down calculations as per Eq.5:

$$
\mathrm{E}(\text { run })_{\mathrm{UD}}=2 \mathrm{~N}-\frac{1}{3}
$$

Where $\mathrm{N}$ is the number of observations and $\mathrm{E}$ (run) $)_{\mathrm{UD}}$ is the expected number of run up and down:

$$
\begin{aligned}
E(\text { run })_{U D} & =2 \times 6-\frac{1}{3}=3.667 \\
\text { And } \sigma_{U D} & =\sqrt{ }(16 \mathrm{~N}-29 / 90)
\end{aligned}
$$

Where $\sigma_{U D}$ is the standard deviation for up and down.

$$
\sigma_{\mathrm{UD}}=\sqrt{ }(16 \times 6-29 / 90)
$$




$$
\begin{gathered}
\sigma_{\mathrm{UD}}=0.8628 \\
\mathrm{Z}_{\mathrm{UD}}=\left\{\mathrm{RUN}_{\mathrm{UD}}-\mathrm{E}(\mathrm{run})_{\mathrm{UD}}\right\} / \sigma_{\mathrm{UD}} \\
\mathrm{Z}_{\mathrm{UD}}=(2-3.667) / 0.8628 \\
\mathrm{Z}_{\mathrm{UD}}=-1.5840
\end{gathered}
$$

$\mathrm{P}_{\mathrm{UD}}=\operatorname{NORMSDIST}(\mathrm{Z})$ when the value of $\mathrm{z}$ is negative (using microsoft formula) $\mathrm{P}_{\mathrm{UD}}=0.056597$. Normally decision making is done with certain margin of error ' $\alpha$ ' \& taken as equal to 0.005 that is there can $5 \%$ chances in arriving at wrong conclusion.

Decision making has been carried out as in the present reserach work. If $\mathrm{P}_{\mathrm{AB}}<\alpha$ OR $/ \& \mathrm{P}_{\mathrm{UD}}<\alpha$ then non-random pattern exist. In the present case $\mathrm{P}_{\mathrm{AB}}<\alpha$ indicates existence of non random pattern. Now exercise of predicting various statistical or drawing conclusions should not be undertaken unless the normality of distribution has been verified. Even if one has a large data, superimposing of normal curve on the histogram it is more difficult task than it to be imagined. For histogram one require minimum of 50 observations, however more the better and for assessing whether the underlying distribution is normal or not becomes more difficult when the number of observations is fewer. For cumulative probability plot $(\mathrm{Pi})$ has been calculated using Eq.8:

$$
\mathrm{Pi}=(\mathrm{S} . \mathrm{N}-0.5) / \mathrm{N}
$$

Where S.N is serial number of data observation arranged in ascending order, $\mathrm{N}$ is total number of observations in the data set. If the standard normal deviate follows normal distribution that has mean $\mu$ $=0$ and standard deviation $\sigma=1$, then:

$$
f(Z)=1 / \sqrt{ }\left(2 \Pi e^{\frac{z^{2}}{2}}\right)
$$

The equation above follows normal probability curve and any date close to it also follows normal probability curve. The values of standard normal deviate were calculated using cumulative probability and dimensional values were arranged in ascending order as shown in Table 7.

Based on Table 7, normal probability curve was drawn to predict the probability as shown in Figure-5 and Figure-6. As observed in Figure-5 and Figure-6, the aforesaid data follows non random pattern and is under normal probability curve. So, there are very strong chances that the process is under statistical control however X-bar chart and R-bar chart cannot be drawn due to less number of observational data. The co-efficient of determination $\left(\mathrm{R}^{2}\right)$ having value 0.91 and 0.86 states that the hardness and tensile strength observational values lies in normal probability curve.
Table 7. Standard normal deviate and outer diameter in ascending order.

\begin{tabular}{ccccc}
\hline S.N. & $\mathrm{Pi}$ & $\begin{array}{c}\text { Std. Nor. } \\
\text { Deviate } \\
\mathrm{Z}\end{array}$ & $\begin{array}{c}\text { Observed } \\
\text { hardness } \\
\text { (HRC) }\end{array}$ & $\begin{array}{c}\text { Observed } \\
\text { tensile } \\
\text { strength } \\
(\mathrm{Kgf})\end{array}$ \\
\hline 1 & 0.08333 & -1.38299 & 78.69 & 980 \\
2 & 0.25 & -0.67449 & 78.75 & 979 \\
3 & 0.416667 & -0.21043 & 78.79 & 987 \\
4 & 0.58333 & 0.21043 & 78.86 & 994 \\
5 & 0.75 & 0.67449 & 78.84 & 1003 \\
6 & 0.91667 & 1.382994 & 78.89 & 1001.9 \\
\hline
\end{tabular}

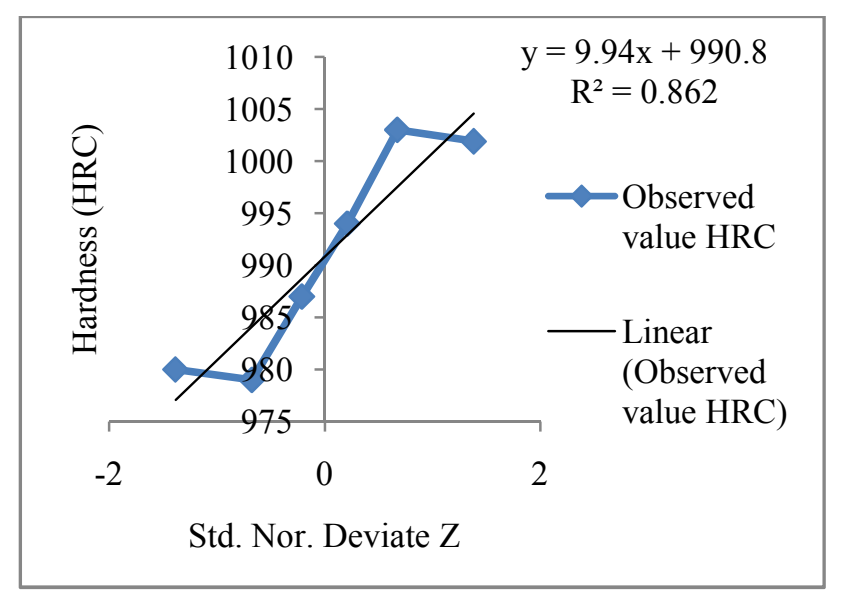

Figure 5. Normal probability curve (for hardness at optimized settings).

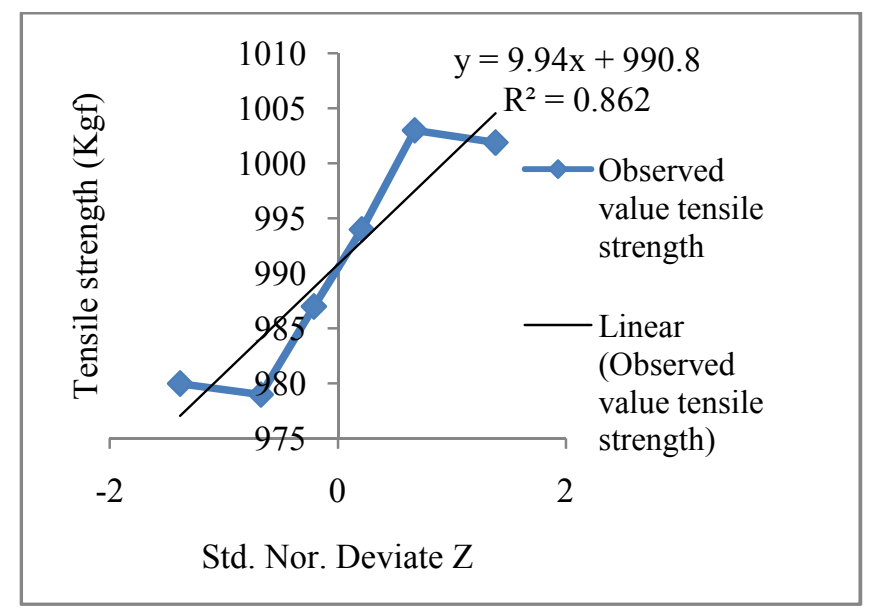

Figure 6. Normal probability curve (for tensile strenth at optimized settings).

\section{CONCLUSIONS}

On the basis of experimental observations made on welded joints of 304SS during RSWP following conclusions can be drawn.

- The results of study highlights the statistically controlled solution for hardness and tensile strength of weld joints are concerned (within the range of selected input parameters) as regards to sensitization in RSWP. 
- The adopted procedure is better for proof of concept. Strong possibilities are observed for the process under statistical control at optimized settings suggested by Taguchi design.

- Hence the process can be used for mass production at proposed settings with controlled sensitization These results are inline with the observations made by other investigators ${ }^{12,13}$.

\section{REFERENCES}

1. Amuda, M.O.H., and Mridha, S., 2011, "An overview of sensitization dynamics in ferritic stainless steel welds", International Journal of Corrosion, Vol. 201, pp.1-9.

2. Atanda, P., Fatudimu, A., and Oluwole, O., 2010, "Sensitization study of normalized 316L stainless steel", Journal of Minerals \& Materials Characterization \& Engineering, Vol.9(1), pp.13-23.

3. Dursun, O., 2008, "An effect of weld current and weld atmosphere on the resistance spot weldability of $304 \mathrm{~L}$ austenitic stainless steel", Materials \& Design, Vol.29, pp.597-603.

4. Hayat, F., Kocabekir, B., Kacar, R., and Gunduz, S., 2008, "An effect of heat input, weld atmosphere and weld cooling conditions on the resistance spot weldability of $316 \mathrm{~L}$ austenitic stainless steel", Journal of Materials Processing Technology, Vol.195, pp.327-335.

5. Li, S., Deng, L., Wu, X., Min, Y., and Wang, H., 2010, "Influence of deep cryogenic treatment on microstructure and evaluation by internal friction of tool steel", Cryogenics, Vol.50, pp.754-758.

6. Sharma, R., 2011, "Effect of cryogenic treatment on sensitization of 304 stainless steel in resistance spot welding“, M.Tech Thesis, Punjab Technical University, Jalandhar.

7. Martin, O., Tiedra, P.D., Lopez, M., and San, J.M., 2011, "Use of EPR test to study the degree of sensitization in resistance spot welding joints of ALSI 304 austenitic stainless steel", Corrosion Science, Vol.4, pp.1563-1570.

8. Muhammad, N., Manurung, Y.H.P., Haruman, E., Abas, S.K., Tham, G., Salleh, K.M., and Chau, C.Y., 2010, "Investigation on weld nugget and HAZ development of Resistance Spot Welding using SYSWELD's customized electrode meshing and experimental verification", Asian Journal of Industrial Engineering, Vol.2, pp. 63-71.

9. Pouranvari, M., 2011, "Effect of welding parameters on the peak load and energy absorption of low-carbon steel Resistance Spot Weld", ISRN Mechanical Engineering, Vol.201, pp.3-7.

10. Singh, R., Singh, S., and Kapoor, P., 2014, "Investigating the surface roughness of implant prepared by combining fused deposition modeling and investment casting", Proceedings of the Institution of Mechanical Engineers, Part E: Journal of Process Mechanical Engineering, DOI: $10.1177 / 0954408914557374$.

11. Singh, J.P., and Singh, R., 2009, "Investigations for statistically controlled rapid casting solution of low brass alloys using three dimensional printing", International Journal of Rapid Manufacturing, Vol.1(2), pp.208-221.

12. Singh, R., 2012, "Effect of work piece volume on statistically controlled rapid casting solution of aluminum alloys using three dimensional printing", Materials and Manufacturing Processes, Vol.27(4), pp.377-382.

13. Singh, R., and Singh, G., 2014, "Investigations for Statistically controlled investment casting solution of FDM based ABS replicas", Rapid Prototyping Journal, Vol.20(3), pp.215-220.

\section{NOMENCLATURE}

$\begin{array}{ll}\text { AB } & \text { Above and below } \\ \text { CFR } & \text { Coolant flow rate } \\ \text { E(run) } & \text { Expected number of run } \\ \text { HRC } & \text { Rockwell hardness C } \\ \text { N } & \text { Number of observations } \\ \text { OA } & \text { Orthogonal array } \\ \text { P } & \text { Probability } \\ \text { Pi } & \text { Commulative probability } \\ \text { RSWP } & \text { Resistance spot welding } \\ \text { S/N } & \text { Signal/noise } \\ \text { S.N. } & \text { Serial no. } \\ \text { UP } & \text { Up and down }\end{array}$

\section{GREEK SYMBOLS}

e Exponential

Mathematical constant equal to a circle's

$\pi$ circumference divided by its diameter

$\mathrm{Z}$ Normal derivate

$\mu$ Mean

$\sigma$ standard deviation

$\alpha$ Error 